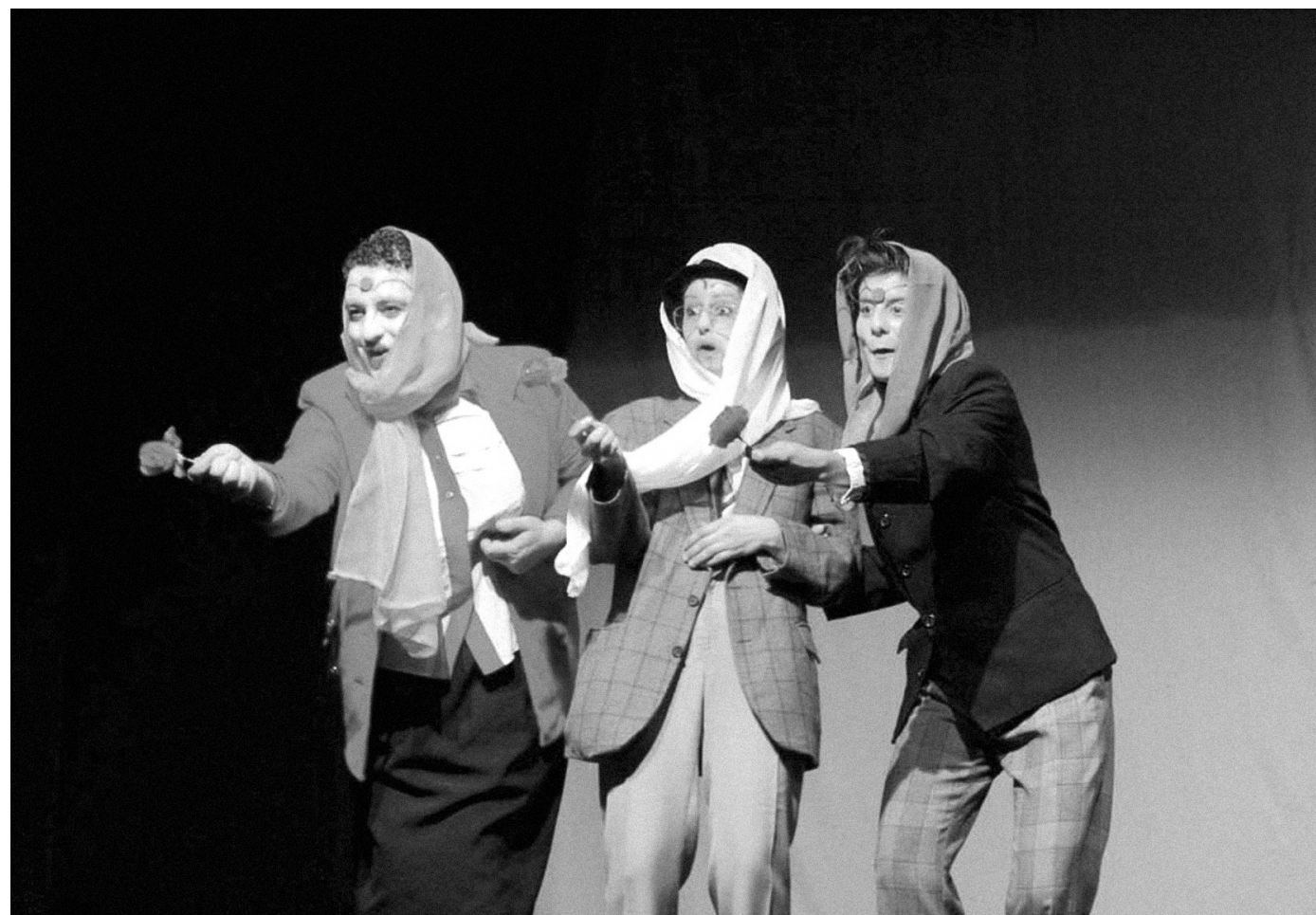

Da ocidental praia

lusitana... por

(impensáveis) mares

nunca antes navegados, texto e enc. Rui Silva,

Grupo de Teatro Ajitar grupo da associação de juventude de Idanha-aNova de teatro amador da Raia, 2008 (Rui Varão, Carla Miguel e Ana Luisa Vasconcelos), fot. Rui Afonso

\title{
Um mundo alternativo, uma nova realidade
}

\author{
Jorge Daniel Chambel Geraldo
}

0 mundo cibernético é hoje em dia um espaço de partilha e um espaço de conhecimento onde a desconfiança de outrora se rendeu a evidências claras no que concerne às vantagens proporcionadas por este novo meio de comunicação. Não podemos achar que os três w's [www] são a resposta para tudo, mas, no que diz respeito ao teatro, muitas portas se abriram, enquanto muitas outras se preparam para ser abertas.

Com isto em mente, não pretendo reflectir sobre um sítio específico da Internet, mas sim sobre o papel da Internet enquanto entidade modeladora e criadora de novos parâmetros, que em tudo beneficiam aqueles que com mais dificuldades se debatem para levar a sua arte até onde Ihes seja possivel. Falo concretamente dos mais "pequeninos", dos outsiders, dos underdogs... falo das companhias de teatro de amadores.

0 mundo do teatro de amadores é por norma um universo de dificuldades, quer técnicas, quer financeiras, quer muitas vezes humanas. Muitas colectividades foram entre nós subsistindo ao longo dos anos através da boa vontade de alguns indivíduos que ardilosamente foram dando continuidade a projectos, em alguns casos com bastantes décadas de existência.

Em muitos casos, a dificuldade do teatro de amadores está intimamente ligada, não à falta de informação, mas à falta de acesso a essa mesma informação. Contudo, a distância em relação à informação foi fortemente mitigada com o acesso desses "amadores" às novas tecnologias, através da troca de informações disponiveis pela Internet, tendo-se desenvolvido esse processo em várias etapas.

Numa primeira fase, começou por existir uma envergonhada aposta, aparecendo por todo o lado pequenos sítios de teatro, que, na maior parte das vezes, não faziam justiça aos grupos em si. Com o maior conhecimento do meio, tudo se tornou menos complicado, passando a existir uma maior aposta que resultou em locais de informação de fácil acesso, com boa apresentação e repletos de informações pertinentes; com a "democratização" da partilha dos ficheiros em formato vídeo, os grupos passaram a ter a possibilidade de se darem a conhecer a uma escala global.

0 mundo cibernético permite que um grupo se reinvente de novas e diversas formas, quer a nivel institucional, quer a nivel estético, quer mesmo a nivel artistico. Nos dias de hoje a presença na Internet tornase imprescindivel. A face visivel de um grupo necessita de existir em formato digital, quer seja através de um sítio de Internet, quer seja através de um mero blogue. Essas formas de comunicação permitem a um grupo expandir a sua divulgação mostrando-se e promovendo-se perante o seu público, mas também perante novos interessados. A partir do momento em que um endereço electrónico está disponivel, fica acessivel ao mais desligado (trocadilho não intencional) viajante da web.

Assim, com a aposta numa vertente cibernética, um grupo amador de teatro pode recriar-se, compondo uma
Jorge Daniel Chambel Geraldo é licenciado em Estudos Artísticos pela Faculdade de Letras da Universidade de Coimbra.

Actualmente, termina a tese de Mestrado na mesma área. 


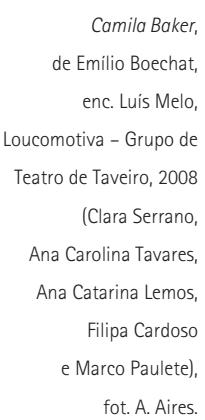

Lenda do Passo do Mouro enc. Leandro Ribeiro, Sol d'Alma, 2007 (Leandro Ribeiro

e André Pinho), fot. Marta Baldaia. imagem apelativa a fim de chegar a novos públicos, divulgando os seus trabalhos, bem como a sua agenda de espectáculos. Pode com facilidade dar informações sobre o seu historial, havendo também espaço de desafio para novos conteúdos que possam abordar o Teatro de forma interpelativa. É com todos estes parâmetros em mente que se torna premente falar de uma nova identidade, já que todos os elementos necessários estão presentes, faltando apenas um - às vezes difícil - impulso inicial, que possa quebrar algumas barreiras intimamente relacionadas com o amadorismo - no pior sentido do termo - que muitas vezes se mostra avesso a qualquer tipo de mudança.

É notório que os grupos de teatro de amadores se vêm rendendo maioritariamente à criação de blogues como o seu meio privilegiado de representação no mundo da Internet. Isto, deve-se à facilidade em criar, manter e gerir esses espaços que são (agora) amplamente usados. Mas, mesmo assim, conseguimos encontrar exemplos diferentes entre blogues que se destinam a um mesmo fim.

0 Grupo de Teatro Ajitar de Idanha-a-Nova, sem um espaço próprio, surge agregado à Associação de Juventude de Idanha-a-Nova (Ajidanha), no endereço http://ajidanha.blogspot.com. Não sendo um espaço dedicado exclusivamente ao Grupo Ajitar, não deixa de ser um espaço privilegiado que este usa de forma hábil, com bastantes informações e actualizações sobre os trabalhos desenvolvidos no passado, assim como sobre os que estão a desenvolver actualmente. Um factor muito positivo está relacionado com a partilha de ficheiros vídeo, dando a possibilidade ao público de acompanhar as produções mais recentes do grupo de Idanha.

De Ovar temos o exemplo do grupo Sol d'Alma, que desenvolveu o blogue http://soldalma.blogspot.com. Tratase do exemplo de um grupo com uma identidade bem definida, marcando presença na Internet com um blogue dedicado, exclusivamente, às diferentes produções teatrais desenvolvidas. É um "pequeno" endereço electrónico, onde podemos encontrar algumas fotografias e muita informação relativa aos espectáculos realizados, constituída por Introdução, Sinopse e Ficha Técnica detalhada. De realçar a inclusão de imagens do que serão o cenário e os figurinos da sua próxima produção, elementos que, ao serem partilhados, aumentam em muito o interesse de quem aguarda pelo próximo espectáculo.

Numa abordagem diferente surge o "recente" Loucomotiva - Grupo de Teatro de Taveiro. Digo diferente porque apostaram num sítio como a sua principal ferramenta de divulgação. Trata-se de um grupo de teatro de amadores com quarenta e um anos de existência e conhecido anteriormente por GAT - Grupo Amador de
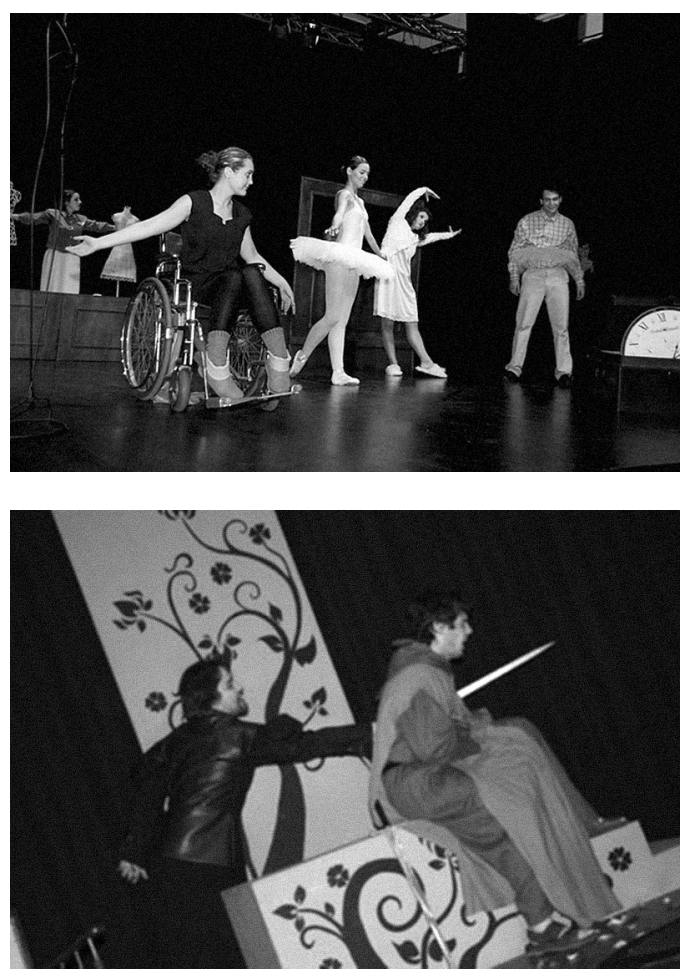

Teatro de Taveiro. No que diz respeito ao reportório que apresentava e a uma reestruturação a nível do elenco, o grupo de Taveiro rejuvenesceu, percebendo que estas mudanças permitiam uma remodelação, ou melhor, uma reinvenção de si próprio enquanto grupo. Foi assim que em 2008 o GATT passou a Loucomotiva, procurando, assim inovar no panorama do teatro de amadores. Aplicaramse na criação de um sítio inovador

(http://www.teatrotaveiro.com), onde se podem encontrar informações diversas, desde a agenda de espectáculos, ao historial de representações, passando por alguns conjuntos de fotografias dos espectáculos mais recentes. A mudança a nivel de imagem institucional potenciou a mudança estética, assim como a mudança de mentalidades em relação ao trabalho desenvolvido. Aqui a Internet não surge como uma mera ferramenta, mas antes assume um papel de destaque numa mudança que demonstra a vontade do grupo de Taveiro em querer chegar a um público mais vasto, transmitindo uma concepção mais alargada daquilo que o teatro amador tem para oferecer.

Estes três exemplos pretendem ser elucidativos das diferentes formas a que os grupos de teatro de amadores se socorrem na sua luta constante para elevar a sua arte a outros patamares. Seja através de um blogue meramente identificativo, passando por blogues repletos de informação, ou sítios apelativos e bem estruturados, a Internet é uma ferramenta relevante na divulgação e valorização dos trabalhos realizados por todo o pais. Devo referir que os três grupos acima citados marcaram presença no CALEse Festival Internacional de Teatro de Amadores 2009 (Porto), festival em que foram todos galardoados.

São três casos bastante distintos entre si, mas umbilicalmente ligados na divulgação de um trabalho comum que procura o seu espaço, tendo encontrado na web um mundo alternativo onde podem existir enquanto expressão - e extensão multimédia - da arte que vão fazendo. 